\title{
Effect of Chemical Sympathectomy on Development of Hypertension in Stroke-Prone and Stroke-Resistant SHR
}

\author{
Hitoshi Ikeda, Masaki Shibota, Akio Shino, \\ Akinobu NagaOKa, and Takeshi FujITA
}

The role of the sympathetic nervous system on development of hypertension in spontaneously hypertensive rats (SHR) was studied by chemical sympathectomy with 6-hydroxydopamine (6-OHDA).

Female and male stroke-prone and stroke-resistant SHR (SHRSP and SHRSR) were used. Three groups of rats were treated with 6-OHDA: The first group (NB-1) was treated with $6-\mathrm{OHDA}(100 \mathrm{mg} / \mathrm{Kg}$, s.c.) at 6,24 , and 72 hours after birth, the second group (NB-8) was given 2 injections of 6 OHDA (200 $\mathrm{mg} / \mathrm{Kg}$, s.c.) on 8 and 15 days after birth and the third group (NB-18) received 5 injections of 6-OHDA according to combination of schedules performed in NB-1 and NB-8 groups. Control rats were subcutaneously injected saline containing ascorbic acid $(0.1 \%)$. Animals were kept on a standard laboratory chow and tap water. Some female rats were given $1 \%$ $\mathrm{NaCl}$ solution for 8 weeks from 12 weeks of age. The systolic blood pressure was measured by a tail pulse-pickup method in unanaesthetized rats. The pressor response to noradrenaline (NA) was measured by the direct method in female SHRSP (20 weeks) under anaesthesia with urethane $(750 \mathrm{mg} / \mathrm{Kg}$, i.p. and $500 \mathrm{mg} / \mathrm{Kg}$, s.c.). Catecholaminergic (CA) neurons in brain and peripheral tissue were detected by the histochemical-fluorescent method.

Body weight gain was less in 3 groups treated with 6-OHDA than that of the corresponding control groups.

The systolic blood pressure was also decreased in the treated groups. The blood pressure was decreased in the following order in SHRSP (male at 11 weeks of age: Control, $200 \pm 7 \mathrm{mmHg}(\mathrm{n}=11)>\mathrm{NB}-1,174 \pm 18 \mathrm{mmHg}$ $(\mathrm{n}=9)>\mathrm{NB}-8,162 \pm 10 \mathrm{mmHg}(\mathrm{n}=5)>\mathrm{NB}-18,156 \pm 14 \mathrm{mmHg}(\mathrm{n}=12) ; \mathrm{fe}-$ male at 12 weeks of age: Control, $184 \pm 14 \mathrm{mmHg}(n=8)>\mathrm{NB}-1,170 \pm 19$ $\mathrm{mmHg}(\mathrm{n}=9)>\mathrm{NB}-8,139 \pm 3 \mathrm{mmHg}(\mathrm{n}=7)>\mathrm{NB}-18,124 \pm 8 \mathrm{mmHg}(\mathrm{n}=8)$. The blood pressure was decreased in NB-18 groups of SHRSR of both sexes. In male rats at 11 weeks of age, the value was $139 \pm 16 \mathrm{mmHg}(\mathrm{n}=11)$ for NB18 and $173 \pm 7 \mathrm{mmHg}(\mathrm{n}=11)$ for control. In female rats at 12 weeks of age,

From the Biological Research Laboratories, Central Research Division, Takeda Chemical Industries, Ltd, Osaka. 
it was $122 \pm 12 \mathrm{mmHg}(\mathrm{n}=8)$ for NB-18 and $161 \pm 6 \mathrm{mmHg}(\mathrm{n}=8)$ for control. The increase of the blood pressure dependent on age was in the order of NB-1 $>$ NB-8 $>$ NB-18 throughout the experimental period. At 20 weeks of age, the absolute value of the blood pressure was in the following order: Control $=$ NB-1 $>$ NB-8 $>$ NB-18.

Load with $1 \% \mathrm{NaCl}$ solution markedly accelerated the rise of the blood pressure dependent on age in either control or treated rats. The increment of the blood pressure after salt load was in the order of NB-8>Control $\fallingdotseq \mathrm{NB}$ $1 \doteqdot \mathrm{NB}$-18. Eight weeks after salt load, the absolute value of the blood pressure was in the following order: Control $=\mathrm{NB}-\mathrm{l}=\mathrm{NB}-8>\mathrm{NB}-18$.

NA increased the blood pressure dose-dependently in control and treated rats at 20 weeks of age. The treatment with 6 -OHDA enhanced the sensitivity to NA in the following order: Control $<$ NB-1 $<$ NB-8 $<$ NB- 18 .

CA fluorescence was completely disappeared in the arterial walls of spleen, kidney, thyroid, gut, and uterus in NB-18 and NB-8 at 20 weeks of age. CA fluorescence in hypothalamus and area solitarius was markedly decreased in NB-18 and NB-1. However, CA neurons in nucleus caudatum and adrenal medulla were not altered in these treated groups.

Administration of 6-OHDA at different stages of newborn SHR resulted in sympathectomy with various severity, shown by the pressor response to NA. Severity of sympathectomy was negatively related to development of hypertension of SHR. The sympathetic nervous system appears to participate in development of hypertension in SHRSP and SHRSR. The peripheral sympathetic tone is more likely to be involved in development of hypertension of these rats than the central sympathetic tone. However, the pressor response to salt, one of genetic characters of SHR, seems to be independent from the sympathetic nervous system, because the treatment with 6-OHDA failed to prevent the increase of the blood pressure after salt load. 